\title{
Grabow, Pharr, and Tsao Will Chair 1995 MRS Spring Meeting April 17-21 1995, San Francisco, California
}

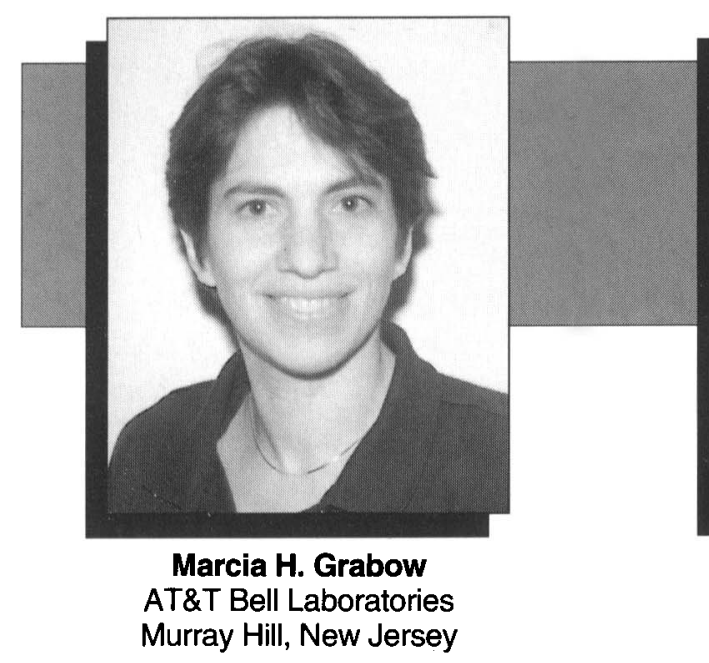

Marcia Grabow, George Pharr, and Jeffrey Tsao, chairs of the 1995 MRS Spring Meeting, have planned an indepth and interdisciplinary technical program with 26 symposia covering a broad range of topics in materials science and engineering. They have encouraged the symposium organizers to include, where relevant, three separate theme areas in their symposia: (1) computational modeling, (2) environmentally conscious manufacturing, and (3) manufacturing and technology road maps. Interdisciplinary connections between symposia will be emphasized and several joint sessions are being planned.

Marcia H. Grabow is a member of the technical staff at AT\&T Bell Laboratories in Murray Hill, New Jersey. A physics graduate of the Massachusetts Institute of Technology, she did her graduate work in materials science and engineering at Stanford University, and joined Bell Labs in 1984 as a postdoctoral fellow. As a postdoc, she used computer simulations to understand issues of growth modes for heteroepitaxial systems, and was involved in a project to build a special-purpose parallel computer which now enables long-time simulations to be performed. Grabow has worked on the rate of phase transformations, investigating both nucleation and growth kinetics, and is now studying the structure and properties of liquids and glasses. She is committed to education both within the profession and for the general public. In addition to her involvement in Materials Research Society meetings, she is a member of the Executive Committee of the Division of
Materials Physics of the American Physical Society. She is also very involved in science education for youth through programs at Bell Laboratories and also within the community as the coordinator of a volunteer science program in Newark, New Jersey.

George M. Pharr is a professor of materials science at Rice University, Houston, Texas, where his research interests center on the mechanisms of deformation and fracture in metals and ceramics, with particular interests in nano-indentation and the mechanical properties of thin films and materials with ultrafine microstructure. A graduate of Rice with a BS degree in mechanical engineering, Pharr received his MS and PhD degrees in materials science and engineering from Stanford University. He joined the faculty of the Department of Mechanical Engineering

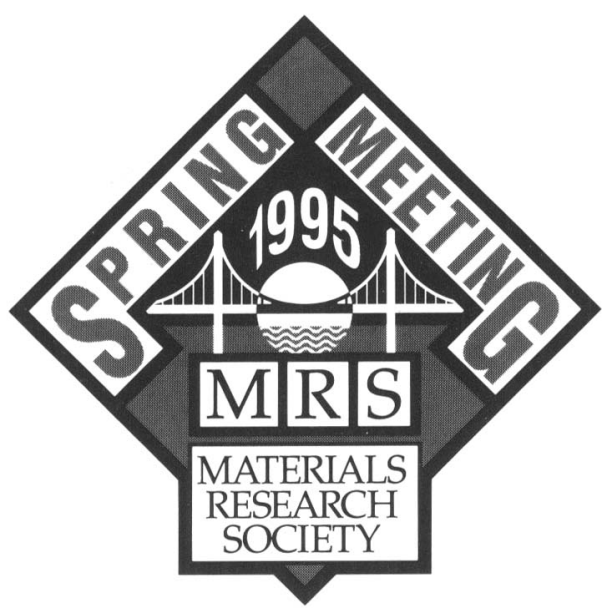

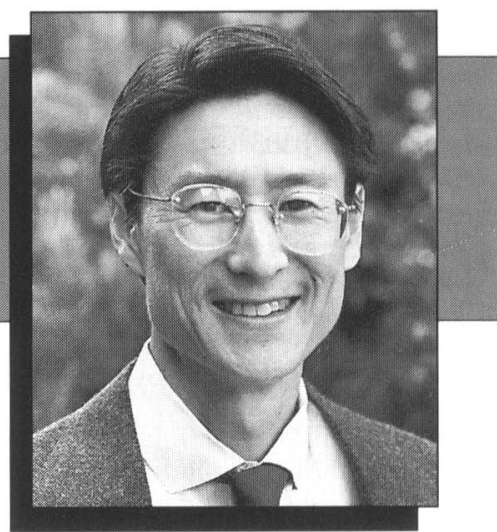

Jeffrey Y. Tsao

Sandia National Laboratories Albuquerque, New Mexico

and Materials Science at Rice University following one year of postdoctoral studies in the Engineering Department of the University of Cambridge, England. In 1987-88 he took a sabbatical as visiting scientist with the Ceramic Sciences Group at the IBM Thomas J. Watson Research Center in Yorktown Heights, New York. Pharr is an associate editor of the Journal of the American Ceramic Society and, in 1985, received ASM International's Bradley Stoughton Award for Young Teachers of Metallurgy.

Jeffrey Y. Tsao is manager of the Semiconductor Materials Department at Sandia National Laboratories. His department is responsible for the development of new epitaxial materials and structures for advanced microelectronic and photonic devices. Tsao received a $\mathrm{BA}$ degree in mathematics and an MS in electrical engineering from Stanford University, and his MS and PhD degrees in applied physics from Harvard University. Following three years on the technical staff of MIT-Lincoln Laboratory, he joined the Sandia technical staff in 1984. Tsao's research has ranged from multiphoton laser chemistry to ultrafast crystal growth and semiconductor epitaxy. His current research focuses on fundamental mechanisms of epitaxy. Tsao has authored or co-authored more than 100 research papers and patents, and has co-edited three books. His monograph, Materials Fundamentals of Molecular Beam Epitaxy was published in 1992. He is a member of the American Physical Society, the American Vacuum Society, and Materials Research Society. 